\title{
Expression and Potential Prognostic Value of SOX9, MCL-1 and SPOCK1 in Gastric Adenocarcinoma
}

\begin{abstract}
Wenyi Luo ${ }^{1,2 *}$, Teddy S. Nagaria 2,3 , Hongxia Sun ${ }^{2,4}$, Junsheng Ma ${ }^{5}$, Jamie L. Lombardo ${ }^{2,6}$, Roland Bassett ${ }^{5}$, Austin C. Cao ${ }^{7}$ and Dongfeng Tan $^{2}$

${ }^{1}$ Department of Pathology, University of Oklahoma Health Sciences Center, Oklahoma City, OK, United States, ${ }^{2}$ Department of Pathology and Laboratory Medicine, University of Texas MD Anderson Cancer Center, Houston, TX, United States, ${ }^{3}$ Department of Pathology, McGill University, Montreal, QC, Canada, ${ }^{4}$ Department of Pathology and Laboratory Medicine, University of Texas McGovern Medical School at Houston, Houston, TX, United States, ${ }^{5}$ Department of Biostatistics, University of Texas MD Anderson Cancer Center, Houston, TX, United States, ${ }^{6}$ Department of Pathology, Walter Reed National Military Medical Center, Bethesda, MD, United States, ${ }^{7}$ Perelman School of Medicine, University of Pennsylvania, Philadelphia, PA, United States
\end{abstract}

Gastric cancer is a common malignancy and remains one of the leading causes of cancerrelated deaths, though its incidence is in decline in most developed countries. One of the major challenges of treating gastric cancer is tumor heterogeneity, which portends a high degree of prognostic variance and the necessity for different treatment modalities. Tumor heterogeneity is at least in part due to divergent differentiation of tumor cells to clones harboring different molecular alterations. Here we studied the expression of emerging prognostic markers SOX9, MCL-1, and SPOCK1 (Testican-1) in a cohort of gastric cancer by immunohistochemistry and investigated how individual biomarkers and their combinations predict disease prognosis. We found frequent expression of SPOCK1 (in both nuclei and cytoplasm), MCL-1 and SOX9 in gastric cancer. In univariate analysis, nuclear SPOCK1 expression and pathologic TNM stage were negative prognostic markers in this cohort. In multivariate analysis, SOX9 expression stood out as a predictor of poor prognosis. Further subgroup analysis suggested prognostic value of SOX9 expression in poorly differentiated gastric adenocarcinoma. MCL-1 showed no prognostic role in this cohort.

Keywords: prognosis, gastric cancer, SPOCK1, SOX9, MCL-1

\section{INTRODUCTION}

Gastric cancer is the fifth most common malignancy in the world and remains the third highest cause of cancer-related mortality after lung and colorectal cancer (1). The incidence of gastric cancer in young adults is increasing, and cancers in these patients are more aggressive and present at a more advanced stage (2).

The outcomes of gastric cancer patients depend on tumor resectability (3). Although the survival in patients after curative resection has improved from $14 \%$ in the 1980 s to $49 \%$ in most recent series, forty to fifty percent of the gastric cancer patients recured $(3,4)$. Eighty percent of gastric cancer patients present with unresectable and metastatic disease (4). The discovery of druggable molecular targets especially HER2/neu and HER2/neu monoclonal antibody therapy have significantly improved the median overall survival (5), suggesting the benefit of additional biomarker discovery. 
TABLE 1 | Antibody information.

\begin{tabular}{lllc}
\hline Antibody & Manufacturer & Clone & Dilution \\
\hline MCL-1 & Cell Signaling & D5V5L & $1: 100$ \\
MUC2 & Cell Marque & MRQ-18 & $1: 300$ \\
MUC5AC & Dako & CLH2 & $1: 50$ \\
SOX9 & Millipore & AB5535 & $1: 200$ \\
CD10 & Leica & $56 C 6$ & $1: 50$ \\
SPOCK1 & Abcam & ab229935 & $1: 500$ \\
HER2 & Ventana & $4 B 5$ & Premade \\
PD-L1 & Dako & $22 C 3$ & Premade
\end{tabular}

The variable prognosis and response to treatment are partially dictated by the heterogeneity of the disease, which is associated with treatment resistance, non-uniform therapeutic effects, and clonal evolution of tumor cells (6). Although gastric cancer can be classified under four major molecular subtypes: Epstein-Barr virus, microsatellite instability, genomically stable, and chromosomal instability, based on predominantly expressed genes (7), the differences within each group are not negligible (8). Additional biomarkers or prognostic factors may be needed to further stratify the tumors in each major molecular subtype (8).

Here we present a study on the expression of emerging biomarkers SOX9, MCL-1 and SPOCK1 in a gastric cancer tissue microarray (TMA). Their correlation with differentiation markers, expression of PD-L1 and HER2/neu and prognosis was also explored.

\section{MATERIALS AND METHODS}

\section{Patients}

The study included 238 consecutive primary gastric cancer patients who underwent surgical resection with no preoperative treatment at the University of Texas MD Anderson Cancer Center between 1987 and 2006. High-density tissue TMA was assembled from selected regions of archived formalin-fixed paraffin-embedded donor tissue containing viable tumor and normal tissue elements as described previouslyf (9). Clinicopathologic parameters collected in this study include age, race, gender, tumor differentiation (classified as well/ moderately differentiated, poorly differentiated or signet ring cell carcinoma), pathologic TNM stage of the tumor and survival. The study was approved by institutional review board (IRB\#: LAB070592).

\section{Immunohistochemistry}

The expression of SOX9, SPOCK1 (Testican-1), MCL-1, MUC2, MUC5AC, CD10, PD-L1 and HER2/neu was assessed by immunohistochemical stains (Table 1).

The immunoreactivity was quantified as described (10) using a weighted histoscore method based on intensity of staining as well as percentage of cell positivity. Thirty percent of total core number was scored by two observers (WL and HS) independently. The HER2/neu immunohistochemical stain was scored based on ASCO and CAP guidelines (11). PD-L1 was scored based on combined positive score with a cutoff of 1 or more (12).
Cases with incomplete data, including the cases whose corresponding tissue cores were lost during staining or cases with no tumor present in corresponding tissue cores, were excluded. Therefore, different number of cases were scored for each marker.

\section{Statistical Analysis}

Categorical variables were summarized by frequencies and percentages and compared between groups with Fisher's exact tests; continuous variables were summarized using medians and ranges, and assessed between groups by Wilcoxon rank sum tests or Kruskal-Wallis rank sum tests. Cox models and Firth penalized Cox models were used to evaluate the associations between survival outcome and covariates of interest.

\section{RESULTS}

\section{Patient and Tumor Characteristics}

The majority of the patients were male Caucasians (59.7\%). The median age at initial diagnosis was 64.1 years (range 28.4-89.6). Patient and tumor characteristics are summarized in Table 2 .

\begin{tabular}{|c|c|c|c|}
\hline Variable & Levels & $\mathbf{n}$ & $\%$ \\
\hline \multirow[t]{3}{*}{ Age } & $\leq 65$ & 124 & 52.8 \\
\hline & $>65$ & 111 & 47.2 \\
\hline & all & 235 & 100.0 \\
\hline \multirow[t]{6}{*}{ Race } & Asian & 32 & 13.4 \\
\hline & Black & 25 & 10.5 \\
\hline & Caucasian & 142 & 59.7 \\
\hline & Hispanic & 35 & 14.7 \\
\hline & Other & 4 & 1.7 \\
\hline & all & 238 & 100.0 \\
\hline \multirow[t]{3}{*}{ Gender } & Female & 88 & 37 \\
\hline & Male & 150 & 63 \\
\hline & all & 238 & 100.0 \\
\hline \multirow[t]{4}{*}{ Tumor differentiation } & Poorly & 85 & 36.8 \\
\hline & Signet ring cell & 47 & 20.4 \\
\hline & Well/Moderate & 99 & 42.9 \\
\hline & all & 231 & 100.0 \\
\hline \multirow[t]{5}{*}{ T stage } & $\mathrm{T} 1$ & 54 & 22.7 \\
\hline & $\mathrm{T} 2$ & 25 & 10.5 \\
\hline & T3 & 106 & 44.5 \\
\hline & $\mathrm{T} 4$ & 53 & 22.3 \\
\hline & all & 238 & 100.0 \\
\hline \multirow[t]{5}{*}{ N stage } & NO & 63 & 28.1 \\
\hline & $\mathrm{N} 1$ & 48 & 21.4 \\
\hline & N2 & 53 & 23.7 \\
\hline & N3 & 60 & 26.8 \\
\hline & all & 224 & 100 \\
\hline \multirow[t]{3}{*}{ M stage } & MO & 205 & 86.1 \\
\hline & M1 & 33 & 13.9 \\
\hline & all & 238 & 100.0 \\
\hline
\end{tabular}



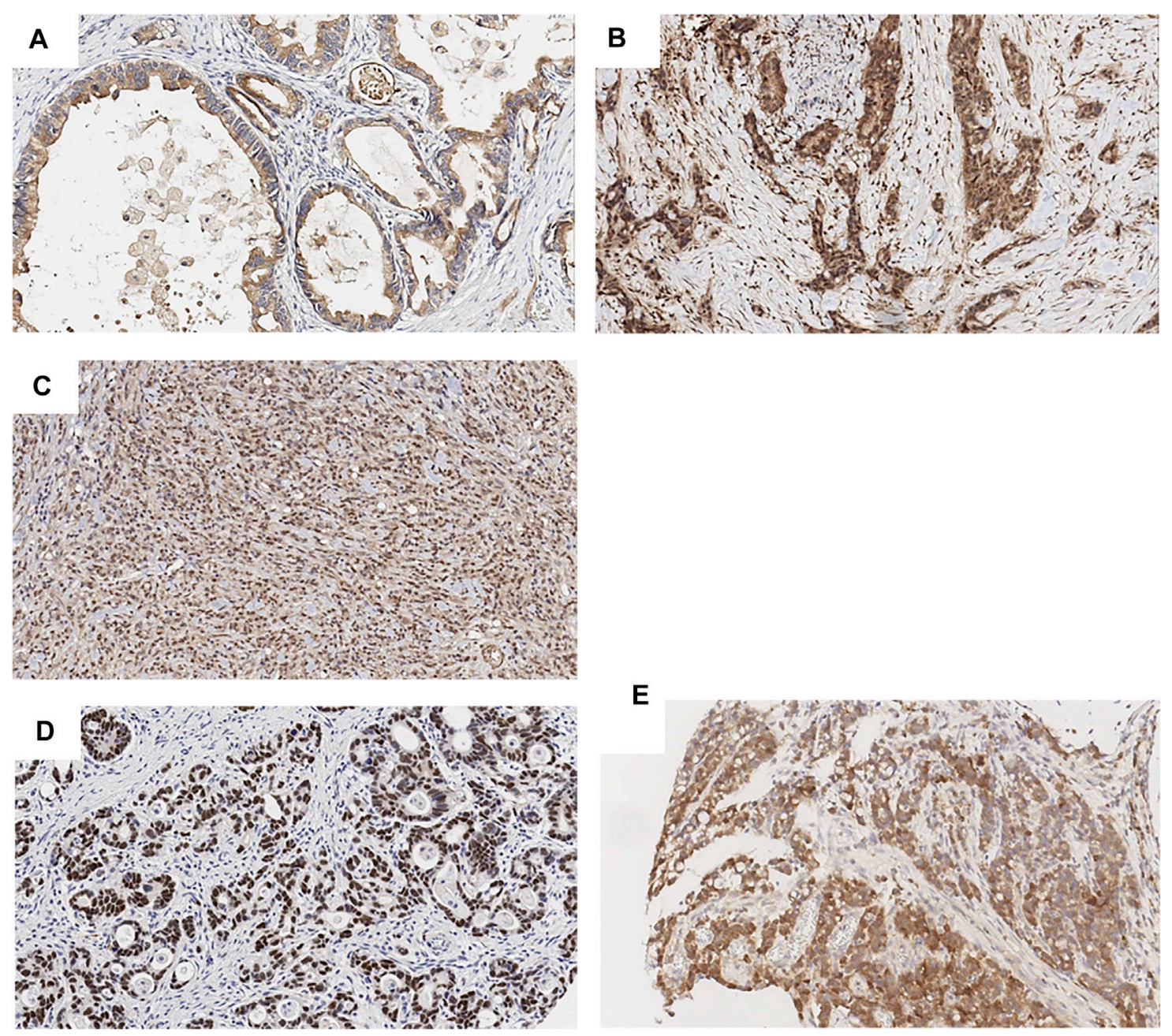

FIGURE 1 | Biomarker expression in gastric cancer (by IHC, ×20). SPOCK1 apical (A), cytoplasmic (B) and nuclear (C) expression. SOX9 nuclear expression (D). MCL-1 cytoplasmic expression (E).

\section{Expression of Biomarkers in Gastric Cancer}

The expression of SOX9, SPOCK1 (Testican-1), MCL-1 was assessed by immunohistochemical stains and correlated with differentiation markers MUC2, MUC5AC, CD10 as well as prognostic/predictive markers $\mathrm{PD}-\mathrm{L} 1$ and HER2/neu. As previously reported, SOX9 showed nuclear stain (13) and MCL-1 showed cytoplasmic staining (14) (Figure 1). SPOCK1, however, showed three different patterns including apical (staining at the apical cell membrane of tumor cells), cytoplasmic and nuclear staining (Figure 1).

Based on how the scores are distributed, SOX9 expression was classified as high, moderated and low. MCL-1 and SPOCK1 expression was classified as high and low. Among 201 tumors scored for SOX9, 64 (31.8\%) showed high expression, 62 (30.9\%) showed moderate expression, and 75 (37.3\%) showed low expression; Among 184 tumors scored for MCL-1, 93 tumors (51\%) showed high expression; Among 144 tumors scored for SPOCK1, 78 tumors (54\%) showed high nuclear expression, 107 tumors
(74\%) showed high cytoplasmic expression, and only 2 cases showed apical membranous expression.

\section{Correlations Between Biomarkers}

SOX9 expression was positively correlated with MUC2 expression $(p=0.01)$ when SOX9 expression was categorized as low, moderated and high. When median was used, high SOX9 expression was associated with male gender $(p=0.036)$, negative PD-L1 $(p=0.034)$ and high SPOCK1 nuclear expression $(p=$ 0.029). MCL-1 expression was associated with well and moderately differentiated tumors $(p=0.026)$ and lower $\mathrm{T}$ stage $(p=0.032)$. However, no correlation was discovered with other clinicopathologic parameters and other biomarker expression using either low, moderated and high expression or median.

\section{Prognostic Value of Biomarkers}

The median survival time was 28.7 (21.8-42.2) months. Univariate analysis (Table 3) demonstrated that high 
TABLE 3 | Univariate analysis for overall survival.

\begin{tabular}{|c|c|c|c|c|c|}
\hline Prognostic Factor & $\mathbf{N}$ & Events & HR & $\begin{array}{l}95 \% \mathrm{Cl} \\
\text { for HR }\end{array}$ & $p$ \\
\hline Age & 231 & 186 & 1.00 & $(0.99,1.01)$ & 0.837 \\
\hline Race & 227 & 186 & & & \\
\hline Caucasian (ref) & 138 & 118 & - & - & - \\
\hline Asian & 32 & 23 & 0.61 & $(0.39,0.95)$ & 0.028 \\
\hline Black & 25 & 23 & 0.79 & $(0.50,1.24)$ & 0.309 \\
\hline Hispanic & 32 & 22 & 0.67 & $(0.43,1.07)$ & 0.092 \\
\hline Gender & 231 & 186 & & & \\
\hline Female (ref) & 88 & 70 & - & - & - \\
\hline Male & 143 & 116 & 1.05 & $(0.78,1.41)$ & 0.745 \\
\hline T stage & 231 & 186 & & & \\
\hline T1 (ref) & 53 & 27 & - & - & - \\
\hline $\mathrm{T} 2$ & 23 & 17 & 1.88 & $(1.02,3.45)$ & 0.042 \\
\hline T3 & 104 & 95 & 3.25 & $(2.11,5.01)$ & $<0.001$ \\
\hline $\mathrm{T} 4$ & 51 & 47 & 4.09 & $(2.53,6.61)$ & $<0.001$ \\
\hline $\mathrm{N}$ stage & 217 & 174 & & & \\
\hline NO (ref) & 61 & 41 & - & - & - \\
\hline N1 & 47 & 36 & 1.22 & $(0.77,1.92)$ & 0.396 \\
\hline N2 & 52 & 46 & 2.25 & $(1.47,3.45)$ & $<0.001$ \\
\hline N3 & 57 & 51 & 2.67 & $(1.76,4.06)$ & $<0.001$ \\
\hline M.stage & 231 & 186 & & & \\
\hline MO (ref) & 198 & 154 & - & - & - \\
\hline M1 & 33 & 32 & 4.24 & $(2.83,6.36)$ & $<0.001$ \\
\hline Tumor differentiation & 225 & 181 & & & \\
\hline Poor & 83 & 67 & - & - & - \\
\hline Signet ring & 46 & 41 & 1.3 & $(0.88,1.92)$ & 0.187 \\
\hline Well/Moderate & 96 & 73 & 0.74 & $(0.53,1.04)$ & 0.079 \\
\hline MUC2 & 194 & 160 & 0.99 & $(0.91,1.08)$ & 0.894 \\
\hline MUC5AC & 195 & 162 & 1.03 & $(0.98,1.07)$ & 0.253 \\
\hline sox9 & 194 & 160 & 1.04 & $(0.98,1.09)$ & 0.206 \\
\hline MCL-1 Median & 180 & 143 & & & \\
\hline 0-39 (ref) & 88 & 71 & - & - & - \\
\hline $40-300$ & 92 & 72 & 1.06 & $(0.76,1.48)$ & 0.735 \\
\hline SPOCK1 apical & 139 & 117 & & & \\
\hline Low (ref) & 128 & 108 & - & - & - \\
\hline High & 11 & 9 & 0.88 & $(0.44,1.74)$ & 0.707 \\
\hline SPOCK1 cyto & 139 & 117 & & & \\
\hline Low (ref) & 35 & 25 & - & - & - \\
\hline High & 104 & 92 & 1.49 & $(0.95,2.32)$ & 0.080 \\
\hline SPOCK1 nucleus & 139 & 117 & & & \\
\hline Low (ref) & 62 & 50 & - & - & - \\
\hline High & 77 & 67 & 1.47 & $(1.00,2.16)$ & 0.047 \\
\hline
\end{tabular}

Bold values are "significant $P$ values".

pathologic TNM stage and nuclear SPOCK1 expression were associated with a worse overall survival, while Asian race was associated with better prognosis. We also fitted multivariate Cox models including covariates of race, $M$ stage, tumor differentiation, SOX9, where these variables had $p$-values less than 0.25 in univariate analysis. As tumor stage of T, $\mathrm{N}$ and $\mathrm{M}$ are highly correlated, we only included $M$ stage as it had more complete data. Other biomarkers or covariates with substantially small number of observations were not included. Multivariable analysis (Table 4) demonstrated that presence of metastasis (pM1) and SOX9 expression were predictors of poor prognosis, while better tumor differentiation was a predictor of good prognosis. In subgroup analyses (Table 4), the prognostic potential of SOX9 expression persisted only in patients with poorly differentiated tumors. MCL-1 was not associated with overall survival.

\section{DISCUSSION}

This study examined the expression and prognostic potentials of several emerging gastric cancer biomarkers. We found SOX9 was frequently expressed in gastric cancer. SOX9 is a transcription factor belonging to SOX (from Sry-related HMG box) family which is characterized by the presence of a conserved HMG DNA-binding domain. In embryogenesis and adulthood, SOX9 regulates cell fate decisions and stem cell maintenance including the gastrointestinal tract (15). SOX9 was found to be overexpressed in a wide range of human malignancies and its expression correlated with tumor aggressiveness (16). In human cancer, its target genes include genes promoting stemness, extracellular matrix, cell adhesion, cytoskeleton remodeling and invasion (17). SOX9-positive cells have characteristics of cancer stem cell. They are capable of self-renewal and differentiation to both SOX9-positive and SOX9-negative populations (18). SOX9-positive cells have high proliferation ability and are involved in epithelial-mesenchymal transition and chemotherapy resistance $(18,19)$. Therefore, SOX9 is considered a cancer stem cell marker. SOX9 is involved in tumor initiation through $\mathrm{Wnt} / \beta$-catenin pathway as well as tumor invasion through activation of $\mathrm{TGFb} / \mathrm{Smad}$ signaling $(17,18)$. Co-activation of NOTCH signaling pathway has also been identified (20). In normal human stomach, SOX9 is predominantly expressed in the neck/isthmus of the pyloric region with a small amount expressed in the neck/isthmus of the corpus (21). In mucosa with intestinal metaplasia, SOX9 expression is located at the base of the mucosa and colocalized in cells with the highest proliferation (21). SOX9 expression is significantly increased in Helicobacter pylori-positive gastric biopsies and its expression is required for bacteria-induced gastric cancer cell proliferation in a $\mathrm{Wnt} / \beta$-catenin pathway dependent manner (19). Similar to our study, a prior study has also demonstrated SOX9 expression is common in gastric cancer (22). The correlation of SOX9 expression with tumor progression is controversial. A few studies suggested that elevated SOX9 expression was associated with either tumor aggressiveness or worse patient survival: One small scale study based on gastric cancer biopsies demonstrated high SOX9 expression was associated with more advanced tumor TNM stage and lower overall survival and disease-free survival (19); Another study only found correlation of SOX9 expression with TNM and clinical stages (23); Two other cohort studies did not find any significant relationship between altered expression of SOX9 protein and clinicopathological parameters including overall survival $(24,25)$. On the contrary, one study found an inverse correlation between SOX9 expression and advanced tumor stage, vessel 
TABLE 4 | Multivariate survival analysis.

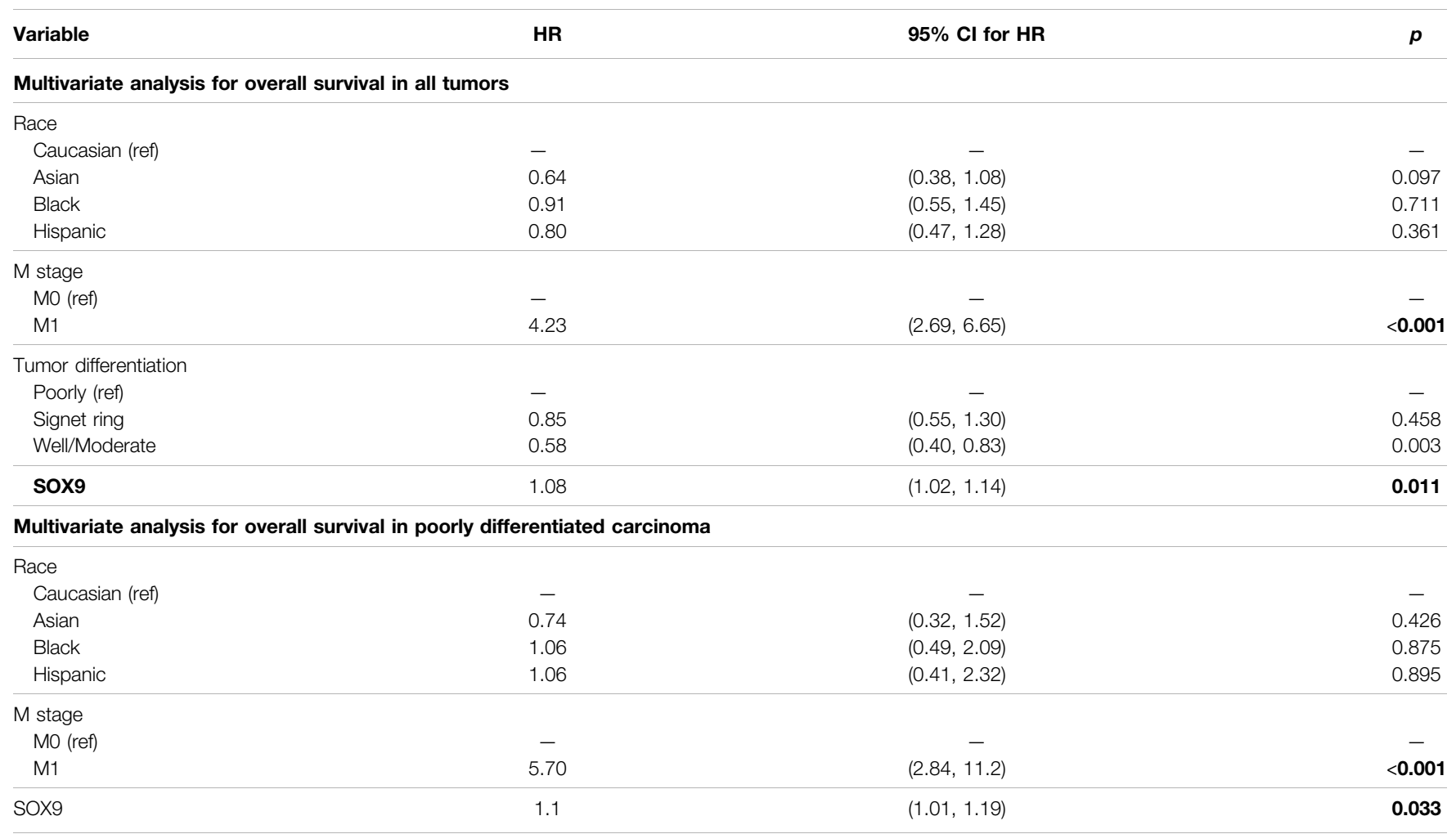

Bold values are "significant $P$ values".

infiltration, nodal metastasis, and EBV infection (22). These contrasting findings may be attributed to varied roles of SOX9 in tumors of different degree of differentiations, tumor stages, patient populations, or dose-dependent effects. In this cohort, SOX9 expression was associated with poor prognosis especially in poorly differentiated tumors. More frequent SOX9 expression found in males might be a recapitulation of its preferential expression in male during the stage of sex development (26). The association of SOX9 expression with MUC2 (an intestinal differentiation marker) expression is consistent with its role in Helicobacter pylori infection and overrepresentation of intestinal-type histology in Helicobacter pylori-related gastric cancers (27). The negative association of SOX9 with PD-L1 suggests gastric cancer with "stem cell features" might be resistant to PD-L1-inhibitor-based immunotherapy.

The study discovered different expression patterns of SPOCK1 and frequent nuclear and cytoplasmic SPOCK1 expression in gastric cancer. SPOCK1 is a matricellular glycoprotein belonging to a novel $\mathrm{Ca}(2+)$-binding proteoglycan family. Members of this protein family including SPOCK1 (TESTICAN-1), TESTICAN2, TESTICAN-3 and SPARC share a similar N-terminus, follistatin-like domain, and C-terminus. They are involved in cell proliferation, adhesion, and migration (28). High tumoral SPOCK1 expression has been associated with increased growth, invasiveness and metastasis in many cancer types (29,30). Although the regulators of SPOCK1 vary in different cancer types, its tumor-promoting effects are predominantly through
PI3K/Akt and Wnt/beta-catenin pathways (31). Stromal SPOCK may be important too because it modifies composition of stromal collagen and enables growth of pancreatic ductal adenocarcinoma in response to tumor-generated TGF-beta (32). The potential importance of SPOCK1 in gastric cancer was first raised in a genome-wide study that found SPOCK1 expression was upregulated 10 -fold in gastric cancer (33). The elevated SPOCK1 expression has been associated with increased metastasis and a poor prognosis in patients with gastric cancer (34). SPOCK1 facilitates gastric cancer cell invasion and metastasis in vitro and mechanism appears to involve Sluginduced epithelial mesenchymal transition (34). In this cohort, the nuclear SPOCK1 expression correlated with a worse overall survival in univariate analysis. In addition, SPOCK1 expression correlated with SOX9 expression. Similar interaction has been identified in neuroblastoma in which significantly decreased SPOCK1 RNA levels were detected in SOX9 knockout neuroblastoma cells (35). These findings suggest potential interaction between two pathways.

Myeloid leukemia cell differentiation protein 1 (MCL-1) is an anti-apoptotic member of the BCL2 family proteins (36). MCL-1's anti-apoptotic function is fulfilled by sequestering pro-apoptotic proteins BAK and BAX (37). In addition to anti-apoptosis, MCL-1 also promotes epithelial-mesenchymal transition of human cancer cells (38). In gastric cancer, MCL1 expression has been correlated with poor prognosis (39) and resistance to chemotherapy (40). Suppression of MCL-1 produced a significant increase in apoptosis and up to $60 \%$ 
decrease in gastric cancer cell growth (41). The expression of MCL-1 in stomach is regulated by hypoxia-inducible factor 1 alpha (HNF1- $\alpha$ ) in Helicobacter pylori-infected human gastric epithelium (42) and HMGB1 in gastric cancer cells (43). Our study did not confirm the prognostic value of MCL-1. We did find, however, that MCL-1 expression was associated with well and moderately differentiated tumors and lower $\mathrm{T}$ stage. These findings are different from prior studies. Since all the prior studies were published on Asian populations, the difference might be explained by different oncogenic etiologies. Alternatively, MCL-1's activity, but not quantity, might be upregulated in poorly differentiated or high stage tumors by post-transcriptional regulation. Since IHC only measures protein quantity, it would not be able to identify the correlation between MCL-1 and tumor aggressiveness.

Our study was limited by drawbacks inherent to TMA such as nonrepresentative tumor sampling and staining artifacts (especially edge artifact). Further validation in full tissue sections is warranted.

\section{DATA AVAILABILITY STATEMENT}

The original contributions presented in the study are included in the article/Supplementary Material, further inquiries can be directed to the corresponding author.

\section{REFERENCES}

1. Rawla P, Barsouk A Epidemiology of Gastric Cancer: Global Trends, Risk Factors and Prevention. pg (2019) 14:26-38. doi:10.5114/pg.2018.80001

2. Bergquist JR, Leiting JL, Habermann EB, Cleary SP, Kendrick ML, Smoot RL, et al. Early-onset Gastric Cancer Is a Distinct Disease with Worrisome Trends and Oncogenic Features. Surgery (2019) 166:547-55. doi:10.1016/j.surg.2019. 04.036

3. D'Angelica M, Gonen M, Brennan MF, Turnbull AD, Bains M, Karpeh MS Patterns of Initial Recurrence in Completely Resected Gastric Adenocarcinoma. Ann Surg (2004) 240:808-16. doi:10.1097/01.sla. 0000143245.28656 .15

4. Ajani JA, Lee J, Sano T, Janjigian YY, Fan D, Song S Gastric Adenocarcinoma. Nat Rev Dis Primers (2017) 3:17036. doi:10.1038/nrdp.2017.36

5. Bang Y-J, Van Cutsem E, Feyereislova A, Chung HC, Shen L, Sawaki A, et al. Trastuzumab in Combination with Chemotherapy versus Chemotherapy Alone for Treatment of HER2-Positive Advanced Gastric or GastroOesophageal junction Cancer (ToGA): a Phase 3, Open-Label, Randomised Controlled Trial. The Lancet (2010) 376:687-97. doi:10.1016/s0140-6736(10) 61121-x

6. Hudler P Challenges of Deciphering Gastric Cancer Heterogeneity. Wjg (2015) 21:10510-27. doi:10.3748/wjg.v21.i37.10510

7. Cancer Genome Atlas Research N. Comprehensive Molecular Characterization of Gastric Adenocarcinoma. Nature (2014) 513:202-9. doi:10.1038/nature13480

8. Lim B, Kim JH, Kim M, Kin SY. Genomic and Epigenomic Heterogeneity in Molecular Subtypes of Gastric Cancer. Wjg (2016) 22:1190-201. doi:10.3748/ wjg.v22.i3.1190

9. Truong CD, Feng W, Li W, Khoury T, Li Q, Alrawi S, et al. Characteristics of Epstein-Barr Virus-Associated Gastric Cancer: a Study of 235 Cases at a Comprehensive Cancer center in U.S.A. J Exp Clin Cancer Res (2009) 28:14. doi:10.1186/1756-9966-28-14

10. Campbell KJ, Dhayade S, Ferrari N, Sims AH, Johnson E, Mason SM, et al. MCL-1 Is a Prognostic Indicator and Drug Target in Breast Cancer. Cell Death Dis (2018) 9:19. doi:10.1038/s41419-017-0035-2

\section{ETHICS STATEMENT}

The studies involving human participants were reviewed and approved by University of Texas MD Anderson Cancer Center. Written informed consent for participation was not required for this study in accordance with the national legislation and the institutional requirements.

\section{AUTHOR CONTRIBUTIONS}

Conception or design of the work: WL and DT. Data collection: WL, TN, HS, JL, and DT. Data analysis and interpretation: JM, RB, WL. Drafting the article: WL. Critical revision of the article: WL, TN, HS, JM, JL, AC, and DT. Final approval of the version to be published: $\mathrm{WL}, \mathrm{TN}, \mathrm{HS}, \mathrm{JM}, \mathrm{JL}, \mathrm{RB}, \mathrm{AC}$, and DT.

\section{CONFLICT OF INTEREST}

The authors declare that the research was conducted in the absence of any commercial or financial relationships that could be construed as a potential conflict of interest.

11. Bartley AN, Washington $M K$, Ventura $C B$, Ismaila N, Colasacco $C$, Benson $A B$, et al. HER2Testing and Clinical Decision Making in Gastroesophageal Adenocarcinoma. Am J Clin Pathol (2016) 146:647-69. doi:10.1093/ajcp/aqw206

12. Kulangara K, Zhang N, Corigliano E, Guerrero L, Waldroup S, Jaiswal D, et al. Clinical Utility of the Combined Positive Score for Programmed Death Ligand-1 Expression and the Approval of Pembrolizumab for Treatment of Gastric Cancer. Arch Pathol Lab Med (2019) 143:330-7. doi:10.5858/arpa.2018-0043-oa

13. Mesquita P, Freire AF, Lopes N, Gomes R, Azevedo D, Barros R, et al. Expression and Clinical Relevance of SOX9 in Gastric Cancer. Dis Markers (2019) 2019:8267021. doi:10.1155/2019/8267021

14. Lee W-S, Park Y-L, Kim N, Oh H-H, Son D-J, Kim M-Y, et al. Myeloid Cell Leukemia-1 Regulates the Cell Growth and Predicts Prognosis in Gastric Cancer. Int J Oncol (2015) 46:2154-1262. doi:10.3892/ijo.2015.2890

15. Kawaguchi Y Sox 9 and Programming of Liver and Pancreatic Progenitors. J Clin Invest (2013) 123:1881-6. doi:10.1172/jci66022

16. Matheu A, Collado M, Wise C, Manterola L, Cekaite L, Tye AJ, et al. Oncogenicity of the Developmental Transcription Factor Sox9. Cancer Res (2012) 72:1301-15. doi:10.1158/0008-5472.can-11-3660

17. Larsimont J-C, Youssef KK, Sánchez-Danés A, Sukumaran V, Defrance M, Delatte B, et al. Sox9 Controls Self-Renewal of Oncogene Targeted Cells and Links Tumor Initiation and Invasion. Cell Stem Cell (2015) 17:60-73. doi:10. 1016/j.stem.2015.05.008

18. Kawai T, Yasuchika K, Ishii T, Miyauchi Y, Kojima H, Yamaoka R, et al. SOX9 Is a Novel Cancer Stem Cell Marker Surrogated by Osteopontin in Human Hepatocellular Carcinoma. Sci Rep (2016) 6:30489. doi:10.1038/srep30489

19. Santos JC, Carrasco-Garcia E, Garcia-Puga M, Aldaz P, Montes M, FernandezReyes M, et al. SOX9 Elevation Acts with Canonical WNT Signaling to Drive Gastric Cancer Progression. Cancer Res (2016) 76:6735-46. doi:10.1158/00085472.can-16-1120

20. Song S, Maru DM, Ajani JA, Chan C-H, Honjo S, Lin H-K, et al. Loss of TGF- $\beta$ Adaptor $\beta 2$ SP Activates Notch Signaling and SOX9 Expression in Esophageal Adenocarcinoma. Cancer Res (2013) 73:2159-69. doi:10.1158/0008-5472.can12-1962

21. Sashikawa Kimura M, Mutoh H, Sugano K SOX9 Is Expressed in normal Stomach, Intestinal Metaplasia, and Gastric Carcinoma in Humans. J Gastroenterol (2011) 46:1292-9. doi:10.1007/s00535-011-0443-5 
22. Sun M, Uozaki H, Hino R, Kunita A, Shinozaki A, Ushiku T, et al. SOX9 Expression and its Methylation Status in Gastric Cancer. Virchows Arch (2012) 460:271-9. doi:10.1007/s00428-012-1201-7

23. Zhou C-J, Guo J-Q, Zhu K-X, Zhang Q-H, Pan C-R, Xu W-H, et al. Elevated Expression of SOX9 Is Related with the Progression of Gastric Carcinoma. Diagn Cytopathol (2011) 39:105-9. doi:10.1002/dc.21348

24. Choi YJ, Song JH, Yoon JH, Choi WS, Nam SW, Lee JY, et al. Aberrant Expression of SOX9 Is Associated with Gastrokine 1 Inactivation in Gastric Cancers. Gastric Cancer (2014) 17:247-54. doi:10.1007/s10120013-0277-3

25. Zhang N, Chai D, Du H, Li K, Xie W, Li X, et al. Expression of Reg IV and SOX9 and Their Correlation in Human Gastric Cancer. BMC Cancer (2018) 18:344. doi:10.1186/s12885-018-4285-x

26. Croft B, Ohnesorg T, Hewitt J, Bowles J, Quinn A, Tan J, et al. Human Sex Reversal Is Caused by Duplication or Deletion of Core Enhancers Upstream of SOX9. Nat Commun (2018) 9:5319. doi:10.1038/s41467-018-07784-9

27. Díaz P, Valenzuela Valderrama M, Bravo J, Quest AFG Helicobacter pylori and Gastric Cancer: Adaptive Cellular Mechanisms Involved in Disease Progression. Front Microbiol (2018) 9:5. doi:10.3389/fmicb.2018.00005

28. Bradshaw AD, Sage EH SPARC, a Matricellular Protein that Functions in Cellular Differentiation and Tissue Response to Injury. J Clin Invest (2001) 107:1049-54. doi:10.1172/jci12939

29. Wang T, Liu X, Tian Q, Liang T, Chang P. Reduced SPOCK1 Expression Inhibits Non-small Cell Lung Cancer Cell Proliferation and Migration through Wnt/ß-Catenin Signaling. Eur Rev Med Pharmacol Sci (2018) 22:637-44. doi:10.26355/eurrev_201802_14288

30. Zhang LQ, Wang Y, Zhang L. Effects of shRNA-Mediated Knockdown of SPOCK1 on Ovarian Cancer Growth and Metastasis. Cel Mol Biol (Noisy-legrand) (2015) 61:102-9. doi:10.14715/cmb/2015.61.7.16

31. Yang J, Yang Q, Yu J, Li X, Yu S, Zhang X SPOCK1 Promotes the Proliferation, Migration and Invasion of Glioma Cells through PI3K/AKT and Wnt/ß-Catenin Signaling Pathways. Oncol Rep (2016) 35:3566-76. doi:10.3892/or.2016.4757

32. Veenstra VL, Damhofer H, Waasdorp C, Steins A, Kocher HM, Medema JP, et al. Stromal SPOCK1 Supports Invasive Pancreatic Cancer Growth. Mol Oncol (2017) 11:1050-64. doi:10.1002/1878-0261.12073

33. Marimuthu A, Jacob HK, Jakharia A, Subbannayya Y, Keerthikumar S, Kashyap MK, et al. Gene Expression Profiling of Gastric Cancer. J Proteomics Bioinform (2011) 4:74-82. doi:10.4172/jpb.1000170

34. Chen D, Zhou H, Liu G, Zhao Y, Cao G, Liu Q. SPOCK1 Promotes the Invasion and Metastasis of Gastric Cancer through Slug-Induced EpithelialMesenchymal Transition. J Cel Mol Med (2018) 22:797-807. doi:10.1111/ jcmm.13357
35. Mondal T, Juvvuna PK, Kirkeby A, Mitra S, Kosalai ST, Traxler L, et al. SenseAntisense lncRNA Pair Encoded by Locus 6p22.3 Determines Neuroblastoma Susceptibility via the USP36-CHD7-SOX9 Regulatory Axis. Cancer Cell (2018) 33:417-34. doi:10.1016/j.ccell.2018.01.020

36. Kaufmann SH, Karp JE, Svingen PA, Krajewski S, Burke PJ, Gore SD, et al. Elevated Expression of the Apoptotic Regulator Mcl-1 at the Time of Leukemic Relapse. Blood (1998) 91:991-1000. doi:10.1182/blood.v91.3.991.991_991_1000

37. Willis SN, Chen L, Dewson G, Wei A, Naik E, Fletcher JI, et al. Proapoptotic Bak Is Sequestered by Mcl-1 and Bcl-xL, but Not Bcl-2, until Displaced by BH3-Only Proteins. Genes Dev (2005) 19:1294-305. doi:10.1101/gad.1304105

38. Lee W-S, Kim N, Park Y-R, Oh H-H, Myung E, Kim S-H, et al. Myeloid Cell Leukemia-1 Promotes Epithelial-Mesenchymal Transition of Human Gastric Cancer Cells. Oncol Rep (2015) 34:1011-6. doi:10.3892/or.2015.4040

39. Maeta Y, Tsujitani S, Matsumoto S, Yamaguchi K, Tatebe S, Kondo A, et al. Expression of Mcl-1 and P53 Proteins Predicts the Survival of Patients with T3 Gastric Carcinoma. Gastric Cancer (2004) 7:78-84. doi:10.1007/s10120-0040272-9

40. Hu C-J, Wang B, Tang B, Chen B-j., Xiao Y-F, Qin Y, et al. The FOXM1Induced Resistance to Oxaliplatin Is Partially Mediated by its Novel Target Gene Mcl-1 in Gastric Cancer Cells. Biochim Biophys Acta (Bba) - Gene Regul Mech (2015) 1849:290-9. doi:10.1016/j.bbagrm.2014.11.008

41. Wacheck V, Cejka D, Sieghart W, Losert D, Strommer S, Crevenna R, et al. Mcl-1 Is a Relevant Molecular Target for Antisense Oligonucleotide Strategies in Gastric Cancer Cells. Cancer Biol Ther (2006) 5:1348-54. doi:10.4161/cbt.5.10.3224

42. Bhattacharyya A, Chattopadhyay R, Hall EH, Mebrahtu ST, Ernst PB, Crowe SE Mechanism of Hypoxia-Inducible Factor 1a-Mediated Mcl1 Regulation in Helicobacter Pylori-Infected Human Gastric Epithelium. Am J PhysiologyGastrointestinal Liver Physiol (2010) 299:G1177-G1186. doi:10.1152/ajpgi. 00372.2010

43. Zhan Z, Li Q, Wu P, Ye Y, Tseng H-Y, Zhang L, et al. Autophagy-mediated HMGB1 Release Antagonizes Apoptosis of Gastric Cancer Cells Induced by Vincristine via Transcriptional Regulation of Mcl-1. Autophagy (2012) 8: 109-21. doi:10.4161/auto.8.1.18319

Copyright (C) 2022 Luo, Nagaria, Sun, Ma, Lombardo, Bassett, Cao and Tan. This is an open-access article distributed under the terms of the Creative Commons Attribution License (CC BY). The use, distribution or reproduction in other forums is permitted, provided the original author(s) and the copyright owner(s) are credited and that the original publication in this journal is cited, in accordance with accepted academic practice. No use, distribution or reproduction is permitted which does not comply with these terms. 